\title{
POSTNATAL DEVELOPMENT OF LAMINAR INNERVATION PATTERNS BY MONOAMINERGIC FIBERS IN MONKEY (MACACA FASCICULARIS) PRIMARY VISUAL CORTEX ${ }^{1}$
}

\author{
STEPHEN L. FOOTE ${ }^{2}$ AND JOHN H. MORRISON ${ }^{3}$ \\ Center for Behavioral Neurobiology, The Salk Institute, La Jolla, California 92138
}

Received October 31, 1983; Revised May 14, 1984; Accepted May 16, 1984

\begin{abstract}
Immunohistochemical methods are used to characterize the distribution of noradrenergic and serotonergic fibers in primary visual cortex of cynomolgus monkeys (Macaca fascicularis) at various postnatal ages. Previous studies in adult squirrel monkeys have shown that serotonergic fibers are generally restricted to the upper four cortical laminae and are especially dense in layer IV, whereas noradrenergic fibers are especially dense in layers V and VI, moderate in layers I, II, and III, and virtually absent in layer IV (Morrison, J. H., S. L. Foote, M. E. Molliver, F. E. Bloom, and H. G. W. Lidov (1982) Proc. Natl. Acad. Sci. U. S. A. 2401-2405; Morrison, J. H., S. L. Foote, D. O'Connor, and F. E. Bloom (1982) Brain Res. Bull. 9: 309-319). Since these monoamines, especially norepinephrine, have been hypothesized to play an essential role in the developmental plasticity of visual cortex organization (e.g., Kasamatsu, T., and J. D. Pettigrew (1976) Science 194: 206-209; Pettigrew, J. D., and T. Kasamatsu (1978) Nature 271: 761-763), the present study examined the postnatal development of these innervation patterns, especially just before and just after the reported "critical period" for visual plasticity. A dense serotonergic innervation of layer IV is present at birth along with sparse innervation of other laminae. The adult pattern of serotonergic innervation, which is similar to that in the squirrel monkey but even more specifically laminated, becomes evident by 6 weeks of age. In the adult pattern, the most dense innervation remains in layers IVb and IVc. A much lower density of noradrenergic than of serotonergic fibers is evident at all ages examined. As with serotonin, the lowest density of fibers is observed at birth. By about 2 months of age these noradrenergic fibers have become more dense, and their laminar distribution is similar to that of adult cynomolgus which is similar to adult squirrel monkey. These studies indicate that: (1) both types of innervation display a continuum of development, with no abrupt changes, (2) serotonergic innervation is more dense than noradrenergic innervation at every age examined, (3) these two transmitter systems exhibit very different laminar innervation patterns as early as birth, and (4) the greater laminar specialization of area 17 in cynomolgus versus squirrel monkeys is accompanied by corresponding enhanced laminar specialization of these monoaminergic afferents.
\end{abstract}

In previous studies, we have shown that noradrenergic (NA) and serotonergic (5-HT) fibers in the primary visual cortex (area 17) of adult squirrel monkeys are distributed in distinct laminar patterns which differ from those evident in other cortical regions (Morrison et al., 1982a, b). Specifically in primary visual cortex NA fibers are most dense in layers $V$ and VI, relatively sparse in layers I, II, and III, and essentially absent in layer IV. In a complementary fashion, 5-HT fibers

${ }^{1}$ This research was supported by National Institutes of Health Grants NS-16209 and NS-18023 to S. L. F. and by the MacArthur Foundation. Our thanks to Steve Scherr, Diana Cohen, and the Salk Institute Photo Lab for excellent technical assistance. F. E. Bloom generously provided facilities and resources for these studies.

${ }^{2}$ To whom correspondence and reprint requests should be sent, at his present address: Department of Psychiatry (M-003), University of California, La Jolla, CA 92093.

${ }^{3}$ Present address: Division of Preclinical Neuroscience and Endocrinology, Research Institute of Scripps Clinic, La Jolla, CA 92037. are very dense in layer IV, virtually absent in layers $\mathrm{V}$ and VI, and of intermediate density in layers I, II, and III. The laminar specificity of these innervation patterns implies different roles for these transmitter systems in the processing of visual information in this cortical region. Since 5-HT fibers are especially dense in the same cortical laminae as geniculocortical terminals, they may well preferentially innervate the spiny stellate cells which are the initial recipients of this thalamocortical innervation (see Lund, 1981, for review). In contrast, the distribution of NA fibers is suggestive of a termination onto pyramidal neurons, the predominant cells of origin for projections out of area 17 (see Lund, 1981, for review).

These observations are also of interest because other studies (Kasamatsu and Pettigrew, 1976; Pettigrew and Kasamatsu, 1978; Kasamatsu, 1983) have raised the possibility that monoaminergic innervation, especially of the NA type, may play a crucial role in the physiological and anatomical plasticity of primary visual cortex which is seen during a postnatal "critical period" in both cats (Wiesel and Hubel, 1963; Hubel and Wiesel, 1970; reviewed in Sherman and Spear, 1982) and mon- 
keys (Hubel et al., 1977; Blakemore et al., 1978; LeVay et al., 1980). This plasticity has been observed to be absent in cats whose primary visual cortex has been treated with the neurotoxin 6-hydroxydopamine (6-OHDA) in such a way as to eliminate NA fibers in the primary visual cortex (Kasamatsu and Pettigrew, 1976; Kasamatsu, 1983). This lack of plasticity can be reversed in 6-OHDA-treated animals and in adults after the critical period by superfusion of noradrenaline (Pettigrew and Kasamatsu, 1978; Kasamatsu et al., 1981). Thus, the possibility exists that there is a change, concomitant with the critical period, in the distribution of NA fibers which provides an anatomical substrate for the onset and/or termination of the critical period. Since the primary events which constitute these plastic changes most likely occur in layer IV (Rakic, 1976; Hubel et al., 1977; LeVay et al., 1978; Shatz and Stryker, 1978), our previous observations on adults raise the possibility that it may be the dense 5-HT innervation of this lamina which subserves plasticity and may show a correlated anatomical change. In contrast, if the NA system plays a dominant role in modulating visual plasticity, our previous data raise the possibility that either there is initially NA innervation of layer IVc which retracts at the end of the critical period, or that plasticity is actually mediated by events in other layers.

In order to characterize the postnatal development of these transmitter systems in primary visual cortex, especially in relation to the visual critical period, we have performed immunohistochemical studies on cynomolgus monkeys (Macaca fascicularis) of various ages from birth to adulthood. This report presents those results and discusses them in relation to the development of this cortical region and in relation to the hypothesis that one or both of these monoamines is critical for visual plasticity. This study extends existing descriptions of monoamine innervation patterns in area 17 of adult Old World monkeys (Takeuchi and Sano, 1983; Kosofsky et al., 1984), and the present results are compared with our previous descriptions of these patterns in a New World species.

\section{Materials and Methods}

The immunohistochemical procedures utilized were the same as those previously described (Morrison et al., 1982a, b). Briefly, deeply anesthetized animals were perfused with ice-cold $1 \%$ paraformaldehyde in phosphate buffer $(0.15 \mathrm{M})$ for 0.5 to $1 \mathrm{~min}$ followed by perfusion with cold $4 \%$ paraformaldehyde in phosphate buffer for 6 to $8 \mathrm{~min}$ at a flow rate of 100 to $500 \mathrm{ml} / \mathrm{min}$ (depending on body size). Tissue blocks, 3 to $5 \mathrm{~mm}$ thick, which included primary visual cortex were removed immediately after perfusion. Postperfusion fixation times were varied depending upon the antigen to be localized in a given block of tissue: material for dopamine $\beta$-hydroxylase (DBH) localization was postfixed for 0 to $1 / 2 \mathrm{hr}$, and that for 5 -HT localization was postfixed for 4 to $6 \mathrm{hr}$. After postfixation, tissue blocks were washed in a series of cold sucrose solutions and stored in $18 \%$ sucrose buffer. The antiserum for visualizing NA fibers was directed against $\mathrm{DBH}$, the final synthetic enzyme for norepinephrine, which was purified from human pheochromocytoma as previously described (O'Connor et al., 1979; Frigon et al., 1981). The antiserum directed against serotonin was that prepared by Lidov et al. (Lidov et al., 1980; Lidov and Molliver, 1982a), using the method of Steinbusch et al. (1978). Evidence supporting the specificity of these primary antisera is presented in our previous reports

\section{1-DAY}

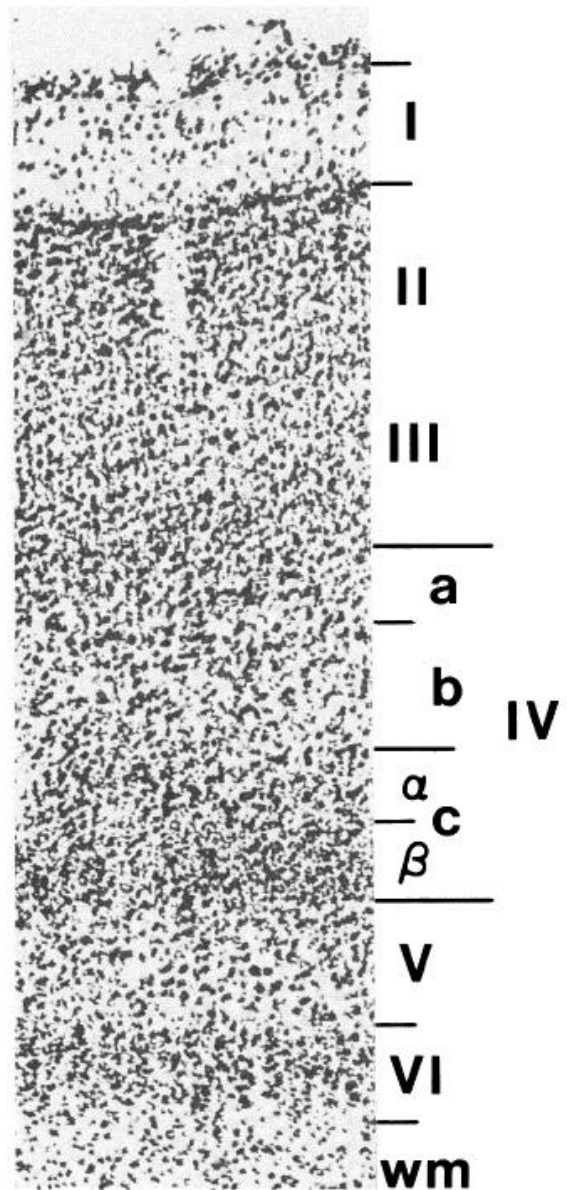

60-DAY

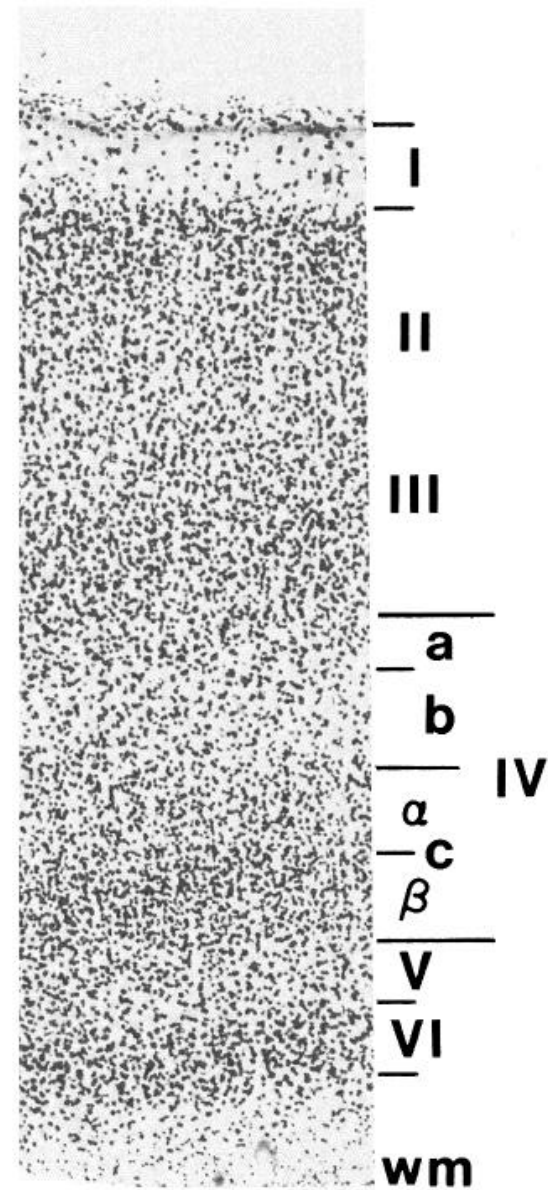

ADULT

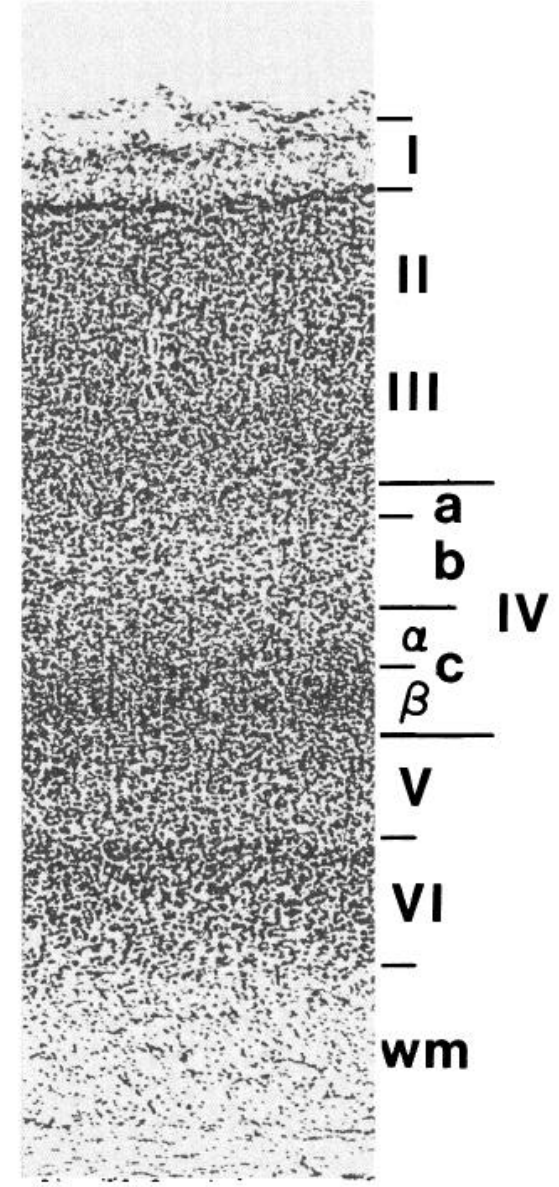

Figure 1. Nissl-stained sections from area 17 of 1 -day-old, 60 -day-old, and adult monkeys. These $40-\mu \mathrm{m}$ thick sections were adjacent to sections used for immunohistochemical analysis. The laminar boundaries for each age are indicated to the right. The total thickness of the cortical mantle (brain surface to white matter) for each section was: $1150 \mu \mathrm{m}$ (1-day), $1350 \mu \mathrm{m}$ (60-day), and $1600 \mu \mathrm{m}$ (adult) (measurements not corrected for shrinkage). $w m$, white matter. 


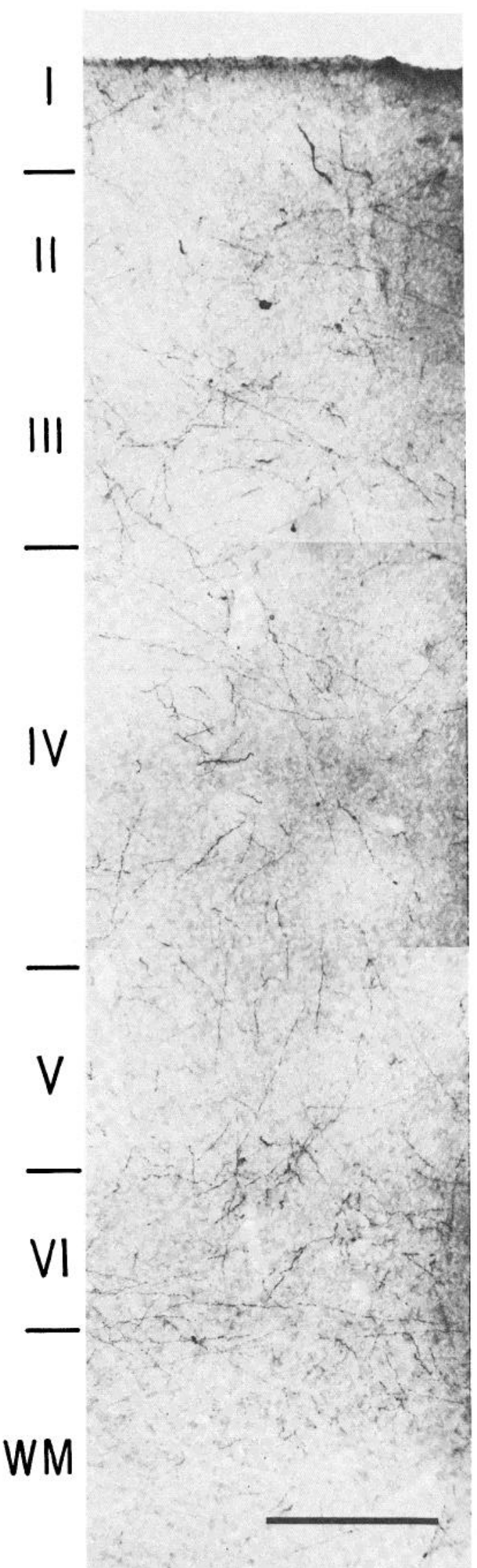

Figure 2. NA fibers in primary visual cortex of a 1-day-old animal. DBH-immunoreactive fibers are shown in a brightfield image of a 40 $\mu \mathrm{m}$ thick section. Cortical laminae are indicated at the left. $W M$, white matter. Calibration bar $=200 \mu \mathrm{m}$.
(Morrison et al., 1982a, b). Freely floating tissue sections 40 or $50 \mu \mathrm{m}$ thick were reacted with one of the primary antisera at a dilution of 1:3000 (DBH) or 1:2000 (5-HT). Primary antibodies were visualized using either a secondary antiserum of peroxidase-conjugated antirabbit IgG (1:1000) or biotinylated anti-rabbit IgG which was subsequently reacted with biotinylated horseradish peroxidase (HRP) (Vector Laboratories, Irvine, CA). The sections were developed for peroxidase reactivity with $3,3^{\prime}$-diaminobenzidine. Visual cortices from eight animals of the following ages were studied: 1 day (two animals), 18 days, 23 days, 60 days (two animals), 5 years, and 8 years. Sections from these cynomolgus brains were compared to similarly processed tissue from 14 squirrel monkeys ranging from 1 day to 11 years of age. They were also compared to sections obtained from prenatal Macaca mulatta fetuses whose visual cortices had been fixed by immersion. In all cases, laminar distribution patterns were determined by careful comparison of the immunohistochemical sections with adjacent Nisslstained sections (see Fig. 1) and by Nissl counterstaining of the immunohistochemical sections. These steps were especially important since the absolute and relative thicknesses of laminae were found to vary with age and with plane of section. Laminae were numbered according to the criteria of Lund (1973). In order to display the small caliber monoamine fibers accurately in terms of their distribution

\section{1 day}

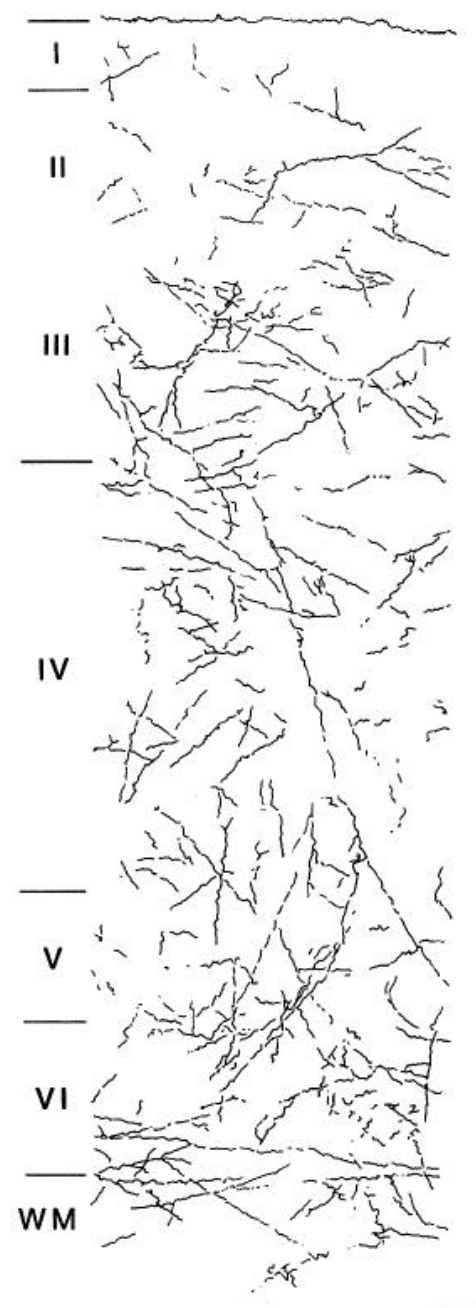

Figure 3. Distribution of NA fibers in primary visual cortex of a 1day-old animal. This illustration is an accurate tracing of the DBHimmunoreactive fibers in the photomontage shown in Figure 2 except that the caliber of fibers has been slightly enlarged for clarity. The method used to produce this tracing is described under "Materials and Methods" and is the same as that used for the other tracings shown in other figures. Cortical laminae are indicated on the left. WM, subcortical white matter. Calibration bar $=200 \mu \mathrm{m}$. 
across all cortical laminae, it was necessary to make tracings from photomontages. Large photomontages were assembled for 5-HT and DBH material from each age. Tracing paper was then placed over the montages, and each reactive fiber was carefully drawn. This method increases contrast and permits visualization of these fine fibers over the large areas that must be displayed to perceive lamination patterns. A photomontage and the tracing prepared from it are presented as Figures 2 and 3.

\section{Results}

\section{General observations}

As we have reported previously for the adult squirrel monkey, the overall density of NA fibers in area 17 of young cynomolgus was lower than that of 5-HT fibers, and the density of NA fibers was lower in primary visual cortex than in most other neocortical regions. There was a striking increase in the density and arborization of both types of fibers between birth and 60 days of age. A continuum of development was evident for both $\mathrm{NA}$ and 5-HT innervation. That is, the patterns evident at birth and at 2 weeks were generally those evident in the adult, and any particular intermediate age always exhibited a pattern intermediate to those exhibited by animals of greater and lesser ages. Immunoreactive fibers visualized using either antiserum had the same general appearance as we have previously reported for the adult squirrel monkey (Morrison et al,, 1982b). In general, 5 -HT fibers were of much finer caliber than NA fibers. However, as is presented in detail below, the youngest animals possessed both NA and 5-HT fibers of as large caliber as those observed in adults. All of our observations were compatible with equal antiserum specificity and sensitivity at the different ages and with the monotonic development of these innervation patterns. For example, in brainstem sections from these same animals both NA and 5-HT fibers were evident in the expected locations and densities.

Detailed results are presented below for each age for the two transmitters. In each section, general observations are followed by a description of layer IV innervation. Layers V and VI (infragranular), and layers III, II, and I (supragranular) are then described, in order.

\section{Noradrenergic innervation patterns}

One-day-old animals. At this age, NA fibers were very sparse, short, randomly oriented, and distributed with equal density throughout layers II through VI (see Figs. 2 and 3). There were virtually no labeled fibers present in layer I. Relative to the majority of fibers observed in older animals, fibers in all layers were straight and coarse, giving the appearance of fibers of passage or preterminal fibers, with little arborization in any layer.

Eighteen-and 23-day-old animals. There was no discernible difference between these two animals in terms of innervation patterns or density for either NA or 5-HT fibers. As is shown in Figures 2 and 4, NA fibers were more dense than at birth and were of sufficient density that the adult innervation pattern was already evident. Even though the overall density of fibers was only about $40 \%$ of that observed in adult animals, the lack of fibers in layer IVc relative to other layers was evident. In certain fields, it appeared that both layers IVa and IVc were devoid of fibers. However, there were many areas in which it was unclear whether layer IVa was devoid of fibers. This is not surprising given the overall low density of fibers. In general, there was little geometric order evident in the fibers seen in
18 day

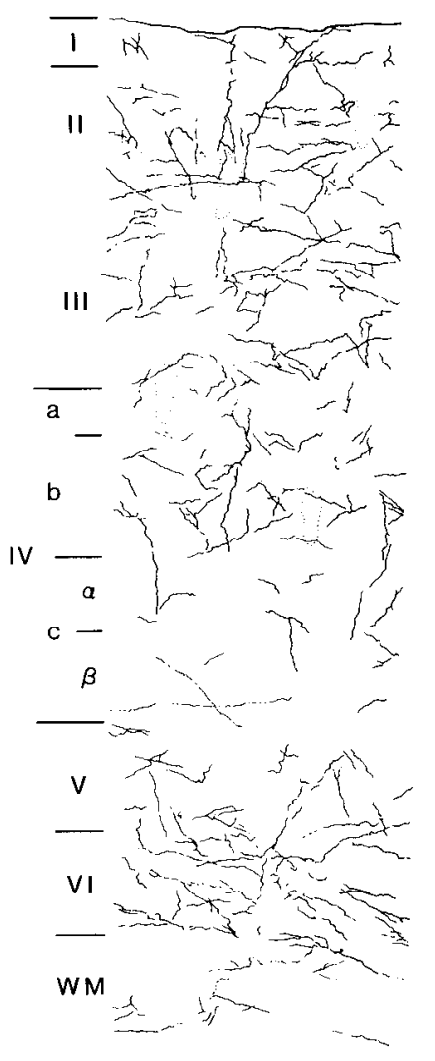

60 day

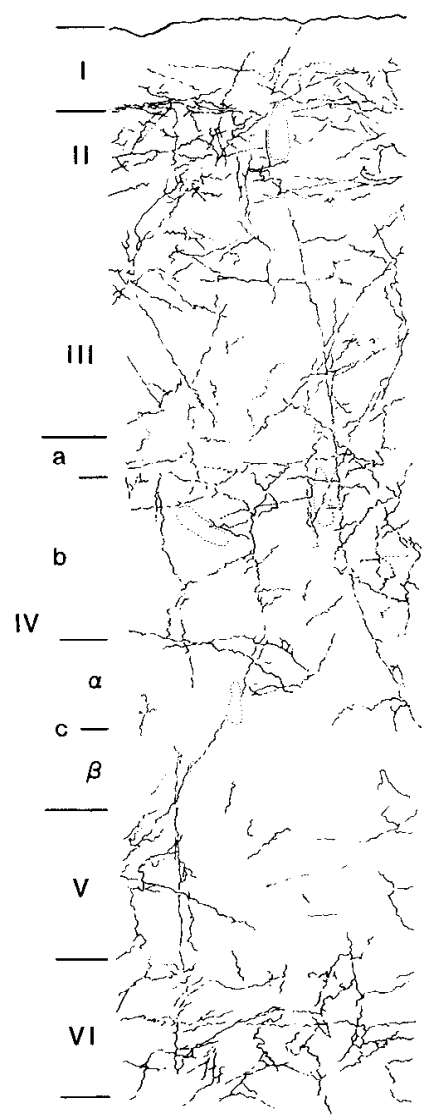

Adult

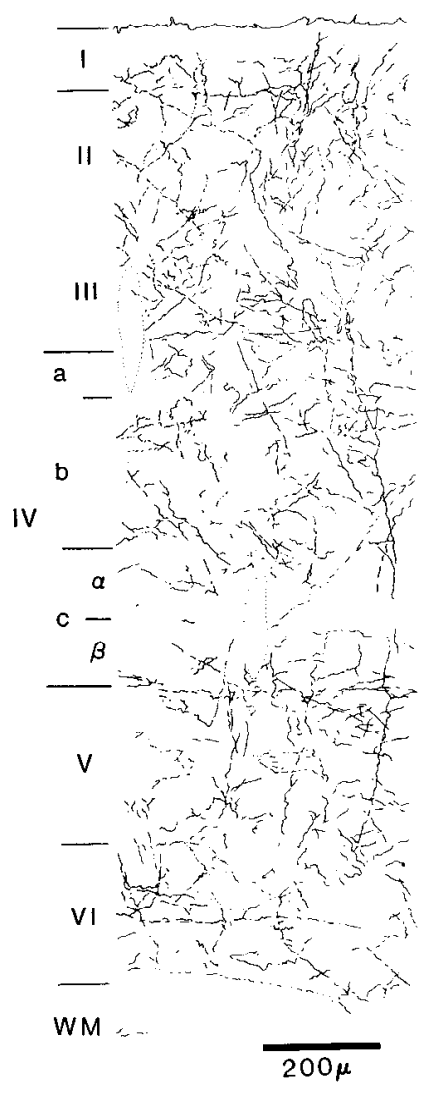

Figure 4. NA fibers in area 17 of 18-day, 60-day, and adult animals. Note the increased density and arborization with increasing age and the correlated appearance of a decreased density of fibers in layer IVc. $W M$, white matter. Calibration bar $=200 \mu \mathrm{m}$. 
layers V, VI, II, and III. The other difference in animals of this age from the adult pattern was that only occasional fibers were evident in layer I (see Fig. 5). Very few fibers were evident in the subcortical white matter.

Sixty-day-old animals. NA fibers in these animals exhibited the adult pattern of innervation but with reduced fiber density in all layers (see Fig. 4). Layer IVc $\beta$ contained only occasional fibers, whereas layer IVc $\alpha$ had slightly more, most of which were oriented perpendicularly to the pial surface. A higher density of moderately ramified fibers was evident in layer IVb. This higher density of fibers diminished somewhat in layer IVa. Layer VI exhibited about twice the density of fibers seen in layer V. Layers II and III showed moderately dense ramified fibers, with density showing a slight decrease in layer II. Layer I contained only sparse fibers.

Adult animals. These animals exhibited a higher density of NA fibers than did younger animals. Thus, in these animals the absence of fibers in layer IVc was especially prominent (see Figs. 4 and 6). Although the exact upper boundary of this fiberdeficient area was slightly variable, layer IVc $\alpha$ contained occasional fibers, whereas layer IVc $\beta$ was consistently devoid of fibers. Layer IVb contained moderately dense, terminal-like fibers which diminished in density in layer IVa. These appeared to be the most densely innervated layers. An increased density of fibers, most of which were tangentially oriented, was found at the IVc-V boundary. The most striking density increase relative to the 60-day animal was in layers $\mathrm{V}$ and VI which exhibited terminal-like fibers with primarily oblique orientations. Layers II and III were uniformly penetrated by radially and obliquely oriented fibers of moderate density. Layer I contained more fibers than were present in younger animals, but this layer had the lowest density other than layer IVc. The subcortical white matter was essentially devoid of fibers.

\section{5-HT innervation patterns}

One-day-old animals. The overall density of 5-HT fibers was greater than that of NA fibers at all ages. At birth, a moderately dense band of 5-HT fibers which was centered on layer IVb was evident (see Figs. 7 and 8). These appeared to be terminal fibers in that they were of extremely fine caliber and had very tortuous trajectories. This plexus extended into layers IVa and IVc $\alpha$ with a slight diminution in density. Fibers were of appreciably lower density in layer IVc $\beta$. The superficial aspect of layer $\mathrm{V}$ contained about the same density of fibers as layer $\mathrm{IVc}_{\beta}$, but the remainder of layer $\mathrm{V}$ and all of the layer VI exhibited only sparse fibers of somewhat larger caliber. Layers II and III were characterized by a low density of fine caliber fibers, whereas layer I contained only rare fibers. The subcortical white matter contained occasional fibers of large caliber.

Eighteen-and 23-day-old animals. The most prominent characteristic of the 5-HT innervation in these animals was a moderately dense network of extremely fine caliber fibers which penetrated all of layer IVb and IVc $\alpha$. These fibers extended into layers IVa and IVc $\beta$ with significantly diminished density. The 5-HT fibers in layer V had a different appearance from those in layer IV, being of somewhat larger caliber, somewhat longer, and having a predominantly tangential orientation. Layers II, III, lower V, and VI exhibited a low density of fibers with no obvious geometric organization. Layer I contained only occasional immunoreactive fibers (see Fig. 9). Many large caliber fibers of passage were evident in the subcortical white matter and at the deepest portion of layer VI.

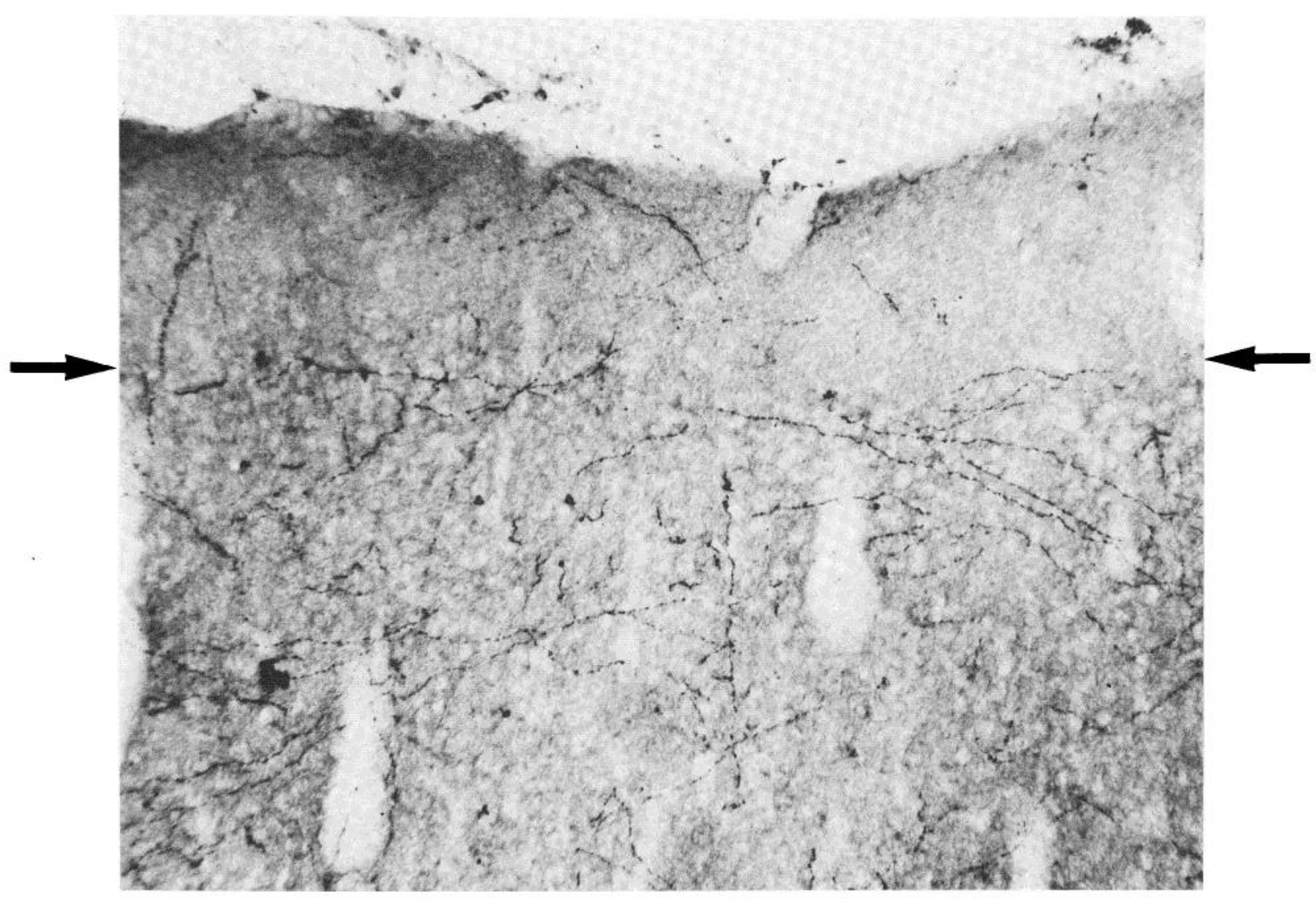

Figure 5. NA fibers in layers I and II of an 18-day-old animal. Arrows indicate the boundary between these two layers. Note the paucity of fibers in layer $\mathrm{I}$. 


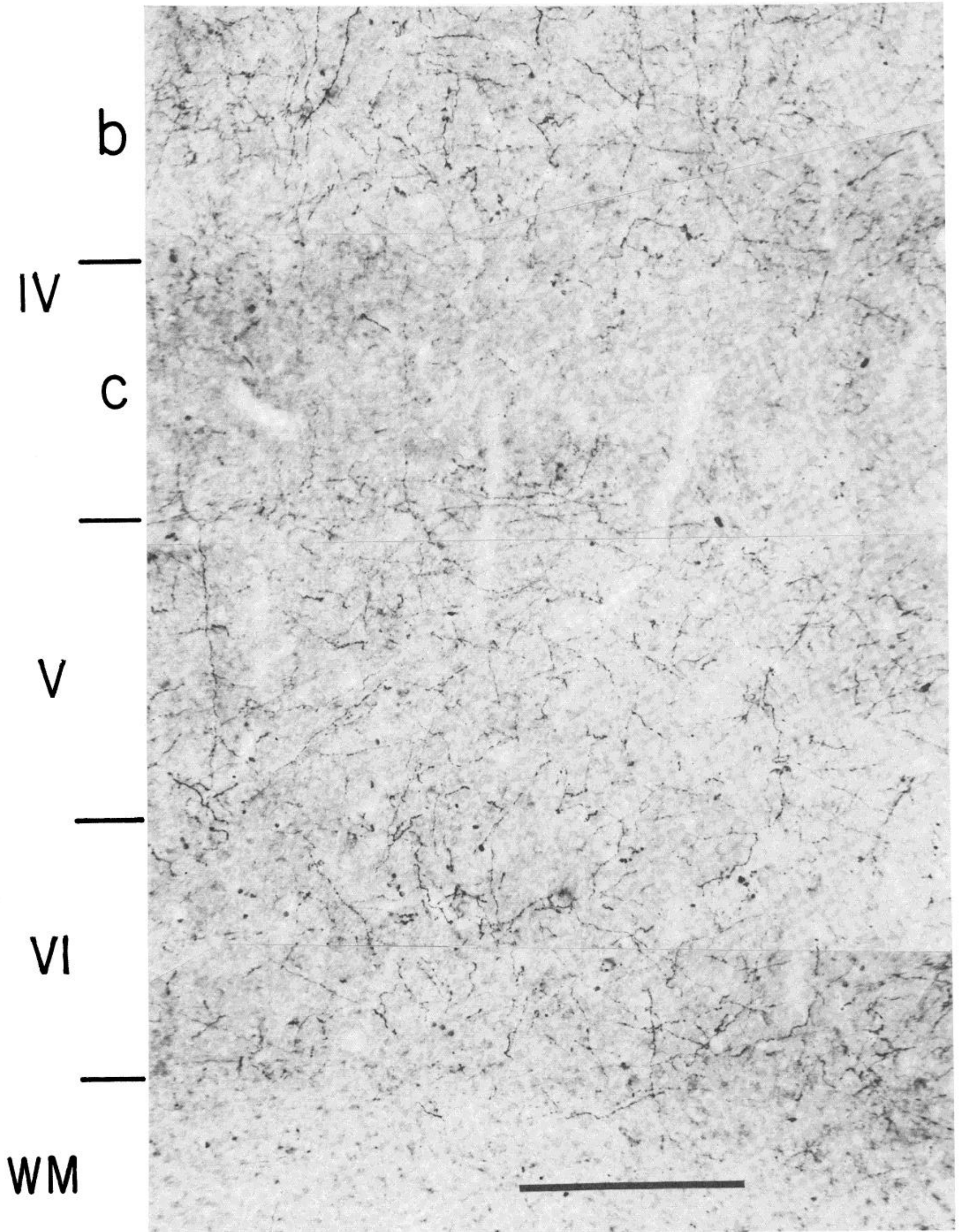

Figure 6. NA fibers in area 17 of an adult animal. This photomontage of a $40-\mu \mathrm{m}$ thick section encompasses the lower portion of layer IV as well as layers V and VI and the adjacent white matter $(W M)$. Note the distinct paucity of fibers in layer IVc. Calibration bar $=200 \mu \mathrm{m}$. 
1 day

Figure 7. Distribution of a 5-HT fibers in area 17 of 1 day old, 60-day-old, and adult cynomolgus. These illustrations are accurate tracings of all 5-HT-immunureactive fibers visible in photomontages. Cortical laminae are labeled for each illustration. $W M$, subcortical white matter. Calibration bar $=200 \mu \mathrm{m}$.

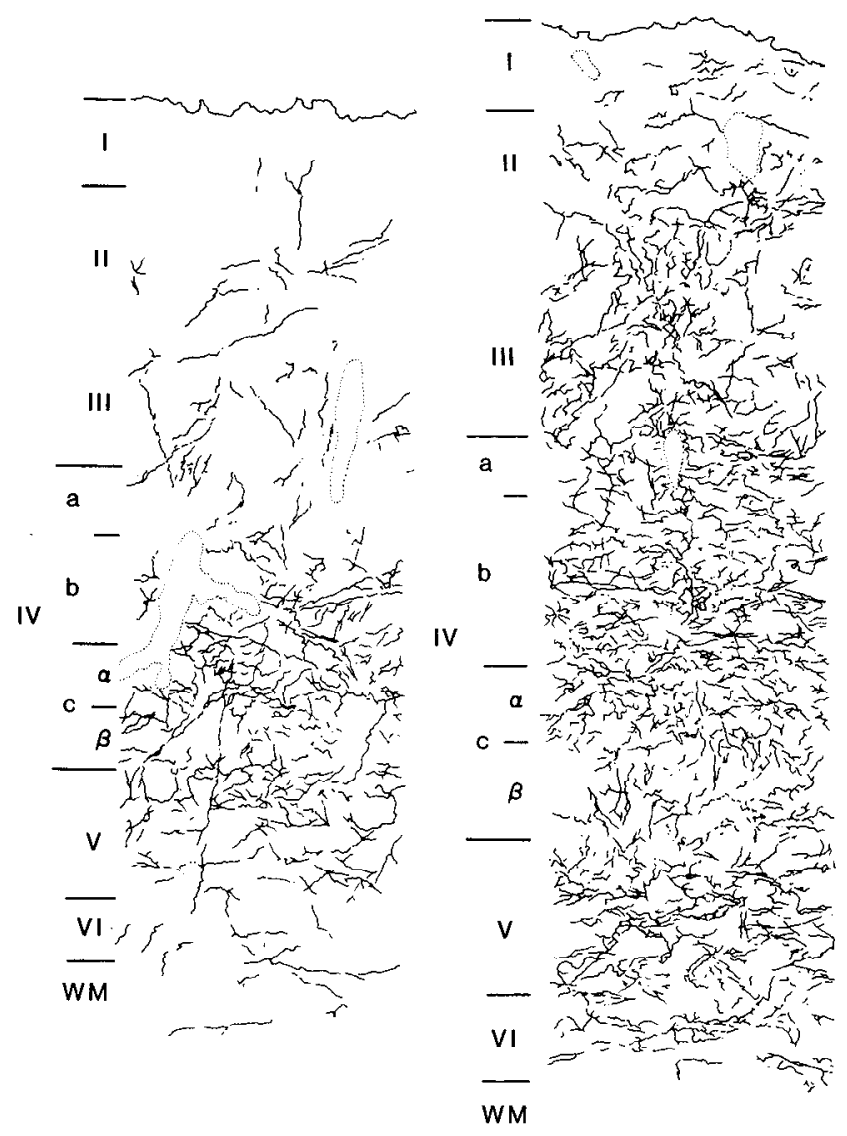

$200 \mu$
60 day

Adult

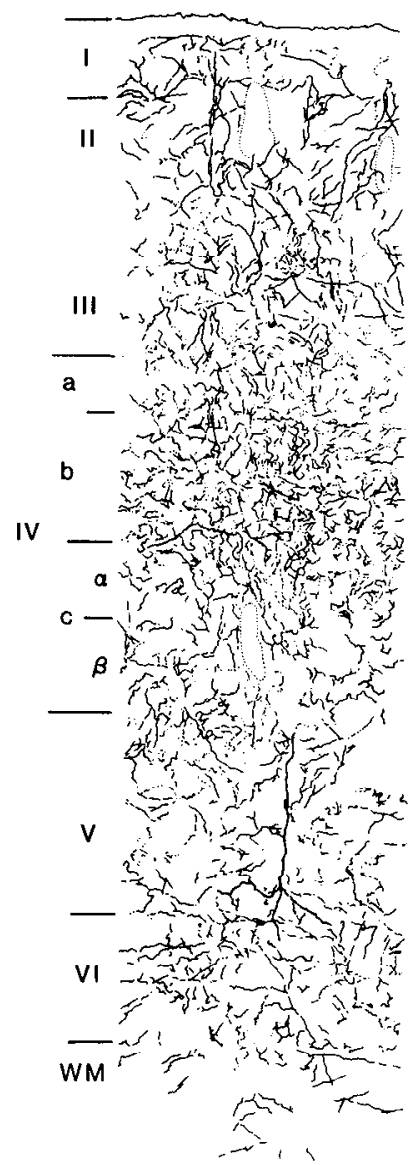

Sixty-day-old animals. As at younger ages, layer IVb was the most densely innervated layer. Its density was greater than that observed in younger animals (see Figs. 7 and 10). I ayer IVa was innervated slightly less densely. Layer IVc $\alpha$ was nearly as densely innervated as layer IVb. Only a low density of fibers was evident in layer $\mathrm{IVc}_{\beta}$, and most of these fibers were oriented perpendicularly to the pial surface. The overall density of fibers in layers $\mathrm{V}$ and VI was much lower than that seen in layers IVa, IVb, and IVc. The same type of plexus that is evident in adult animals was evident in the superficial portion of layer $\mathrm{V}$. Larger caliber, tangentially oriented fibers were seen in layer VI. The 5-HT innervation in these animals was moderately dense in layers II and III, exhibiting a substantial increase over younger animals. These fibers did not show any preferential orientation. Many 5-HT fibers were evident in layer I.

Adult animals. The 5-HT innervation in adult animals retained a dense plexus of very fine fibers through layers IVa, $\mathrm{IVb}$, and IVc $\alpha$ (see Figs. 7 and 11). This plexus was much diminished in layer IVc $\beta$, with a density similar to that seen in younger animals. Layer $\mathrm{V}$ contained few fibers except for a moderately dense horizontal band of fibers in its upper half (see Fig. 12). Many large caliber fibers were evident at the junction of layer VI and the cortical white matter and in the bottom half of layer VI. Layers II and III also exhibited fine caliber fibers but at a much lower density than in the upper parts of layer IV. Many moderate caliber fibers were also evident in layers II and III. Many coarse, tangential fibers were observed in layer I. Only occasional fibers were evident in the subcortical white matter.

\section{Discussion}

These results demonstrate that at birth both NA and 5-HT fibers are present in area 17. NA fibers are very sparse, poorly arborized, and spread throughout all layers. 5-HT fibers are dense, highly arborized, and concentrated in layer IV. Over the following 60 days, both types of fibers increase in density and arborize extensively. By 60 days of age, the adult patterns of innervation are present, although the density of innervation is somewhat lower. These results suggest the following major conclusions. First, there are substantial differences between NA and 5-HT innervation density and pattern throughout the period studied. Second, these patterns develop from an obviously immature state to an essentially mature level within this 60 -day period. Third, there is a smooth transition between birth and adulthood in this development. Fourth, the distinctive sublaminar specialization of area 17 in this species is evident in monoamine innervation patterns in both adult and young animals.

These findings address three major descriptive issues with respect to the existing literature on the monoaminergic innervation of neocortex and its development: (1) species differences in NA and 5-HT innervation patterns in primary visual cortex of adult monkeys, (2) the sequence of development for these patterns, and (3) the timing of these developmental stages. 


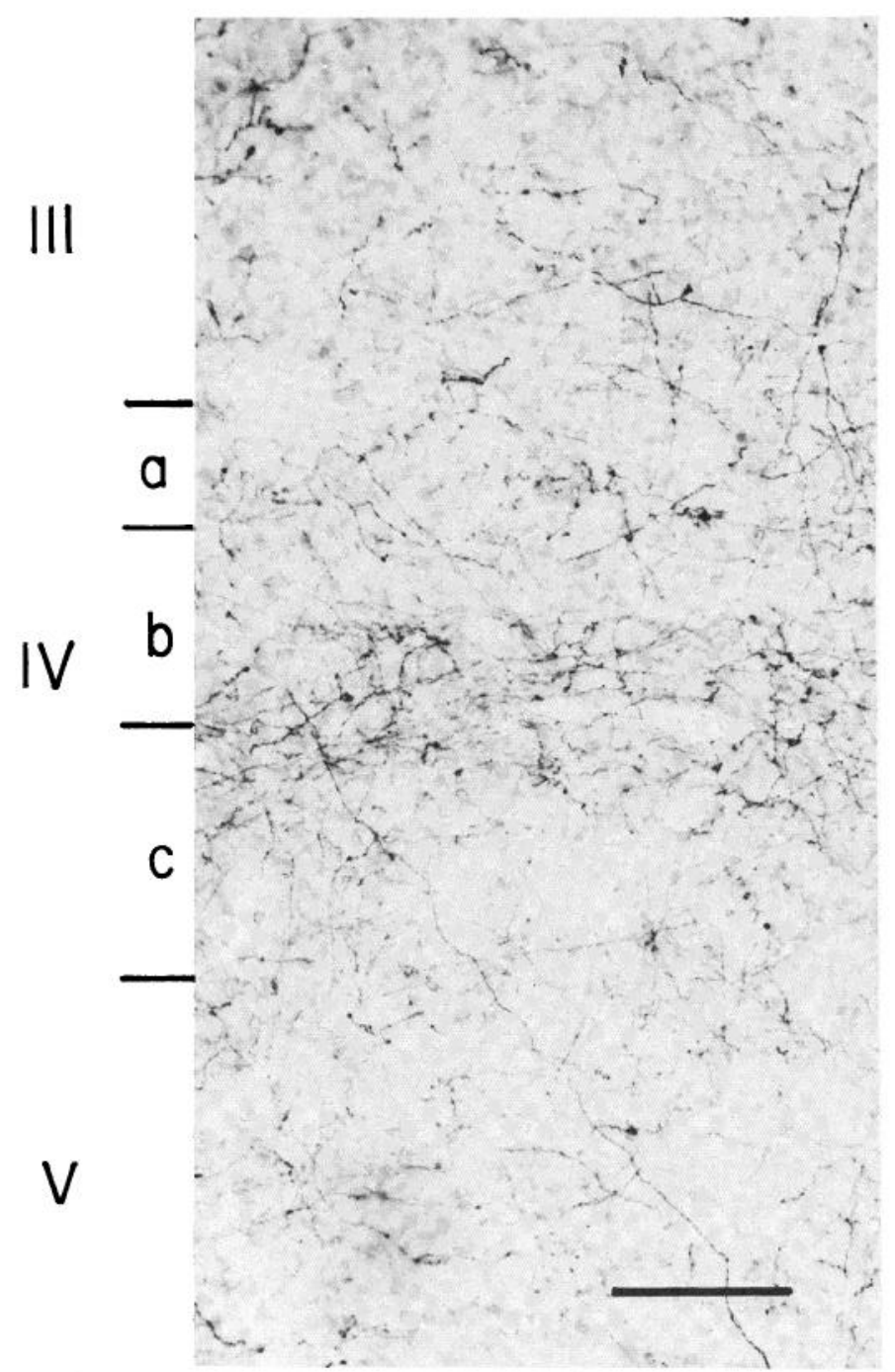

Figure 8. 5-HT fibers in layers III, IV, and V of area 17 in a 1-dayold animal. The greatest density of fibers is centered on the boundary between layers IVb and IVc. Calibration bar $=100 \mu \mathrm{m}$.

These three issues are discussed below, and the data are then presented in terms of the development of other anatomical and physiological features of primary visual cortex and the hypothesis that one or both of these monoamines plays a necessary role in visual cortex development and plasticity.

Species differences. The pattern and density of NA innervation seen in adult cynomolgus monkeys is essentially identical to that observed in adult squirrel monkeys (Morrison et al., 1982a, b; Kosofsky et al., 1984). The most striking feature in both species is the absence of fibers in layer IVc (see Fig. 13 and Kosofsky et al., 1984). One difference between the two species is that layer IVb seems to exhibit a more dense NA innervation in the cynomolgus so that the fiber-poor band is more rigorously restricted to layer IVc. Another difference is that layer I is less densely innervated in the cynomolgus.

The pattern and density of 5-HT innervation in the adult cynomolgus are like those described elsewhere for this species (Kosofsky et al., 1984) and for Macaca fuscata (Takeuchi and Sano, 1983). The pattern of innervation in these Old World species differs from that previously reported for the New World squirrel monkey (Saimiri sciureus; Morrison et al., 1982a) in two major respects. (1) In the Old World species, the innervation of layer IVc $\alpha$ is quite dense whereas the innervation of layer IVc $\beta$ is much less dense. In the squirrel monkey, this sublaminar differentiation of fiber density is not evident (see Fig. 13). (2) In the Old World species, many fibers are evident in layers V and VI, whereas in the squirrel monkey these layers have a very low density of fibers. Many of these fibers appear to be fibers of passage rather than terminally arborizing fibers. Since we utilized the same techniques in the present study that we used to visualize 5-HT fibers in the squirrel monkey, and since our results with Old World monkeys are essentially identical to those of other studies (Takeuchi and Sano, 1983; Kosofsky et al., 1984), we conclude that the observed differences between New and Old World innervation patterns constitute a true species difference, probably reflecting differences in the organization of primary visual cortex in these two distantly related primate species. We also conclude that many of the fibers visible in layers V and VI of the Old World species are fibers of passage and that the general pattern of termination seen in the squirrel monkey is preserved in macaques. In as yet unpublished studies, we have observed that the dense 5-HT innervation of layer IV seen in the cynomolgus monkey at birth is also evident in the squirrel monkey at birth, further emphasizing the interspecies similarities in these innervation patterns.

Developmental sequence. Since previous studies of the development of monoaminergic innervation patterns have been performed in rodents or carnivores, the sequence of developmental events in our study must be compared with findings from these non-primate species. The development of the NA innervation of neocortex has been studied with histochemical techniques in the rat (Seiger and Olson, 1973; Levitt and Moore, 1979; Schlumpf et al., 1980; Specht et al., 1981) and the mouse (Caviness and Korde, 1981). These studies indicate that the innervation is immature but present throughout all regions of the cortex at birth and that it develops gradually thereafter. Initial innervation and later maturation occur along a rostralto-caudal gradient. This is compatible with biochemical data in the rat (Loizou, 1972). There is ultrastructural evidence for a dense monoaminergic innervation of neocortex in the newborn rat (Molliver and Kristt, 1975; Coyle and Molliver, 1977; Kirstt, 1979), although this is difficult to reconcile with light microscopic observations. This early innervation is directed primarily at the primordium of layer IV. HRP injections into infant rat somatosensory cortex have been found to label only locus ceruleus neurons and not raphe cells (Kristt and Silverman, 1980 ), suggesting that in the rat, unlike the monkey, this early innervation of layer IV is noradrenergic.

The development of 5-HT innervation in rat neocortex has been studied with immunohistochemical methods (Lidov and Molliver, 1982a). Like NA afferents, 5-HT fibers initially enter the cortical anlage as two tangential and parallel sheets, one above and one below the cortical plate. Also like NA afferents, 5 -HT fibers gradually extend in a caudal direction so that the occipital region is among the last to be innervated. Finally, like NA afferents, 5-HT fibers gradually penetrate the middle layers of cortex from above and below to generate terminal arborizations. Although this sequence of events is similar for the two transmitters, these events occur earlier for the NA system. NA innervation achieves adult density and pattern by the 7 th postnatal day (Lidov et al., 1978; Levitt and Moore, 1979), whereas the 5-HT innervation approaches the adult density by 3 weeks of age (Lidov and Molliver, 1982a; Molliver, 1982). Thus, in the rat, 5-HT terminals may be one of the last extrinsic afferents to innervate the cortex.

These results from rodents differ substantially from the present results in two regards: (1) for 5-HT, and possibly for NA, our results do not suggest that innervation proceeds in the outside-in pattern so evident in rodents, and (2) in the primate, 5-HT innervation develops earlier than NA innervation and is 


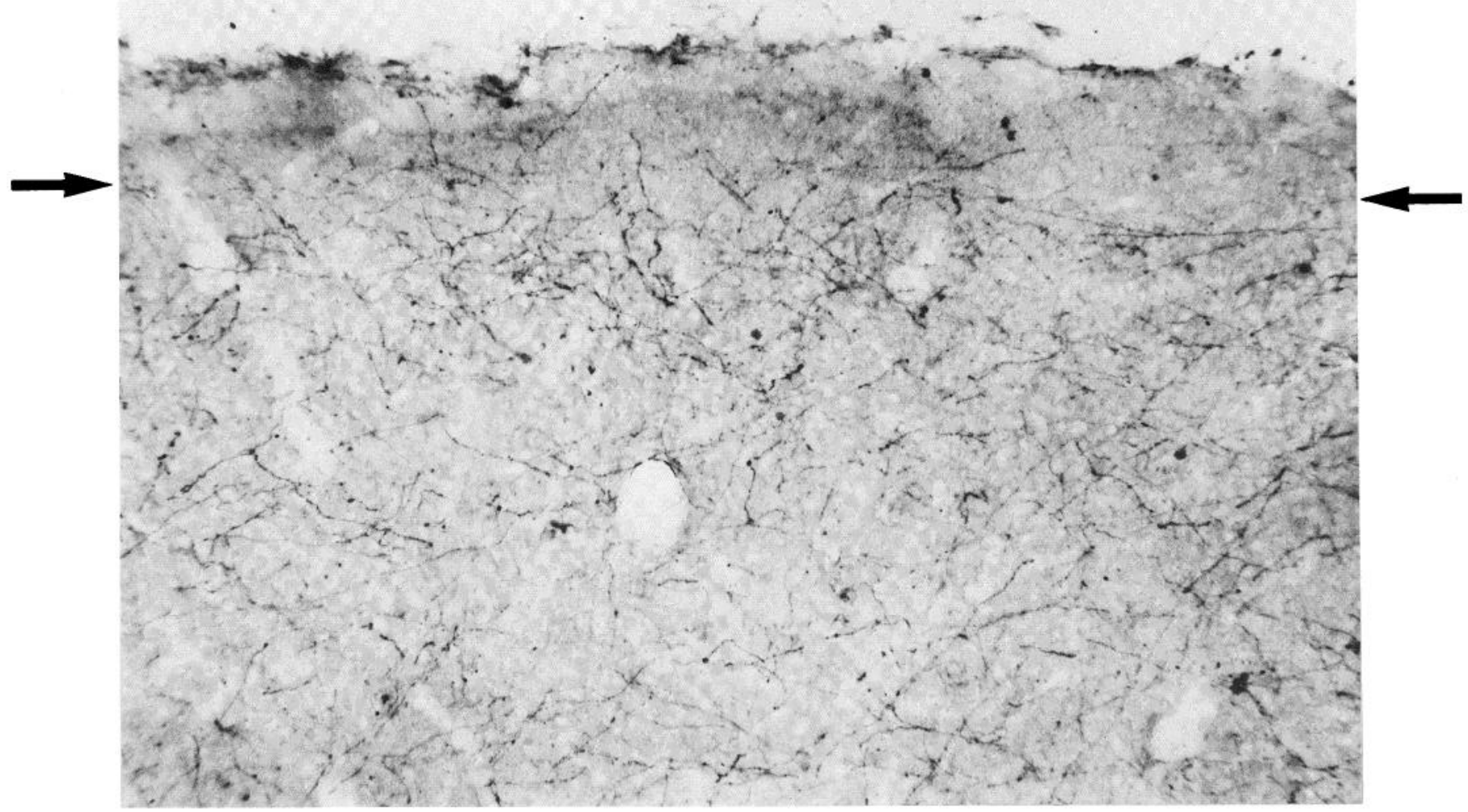

Figure 9. 5-HT fibers in layers I and II of area 17 in an 18-day-old animal. Arrows indicate the boundary between these two layers. Note the paucity of fibers in layer $\mathrm{I}$.

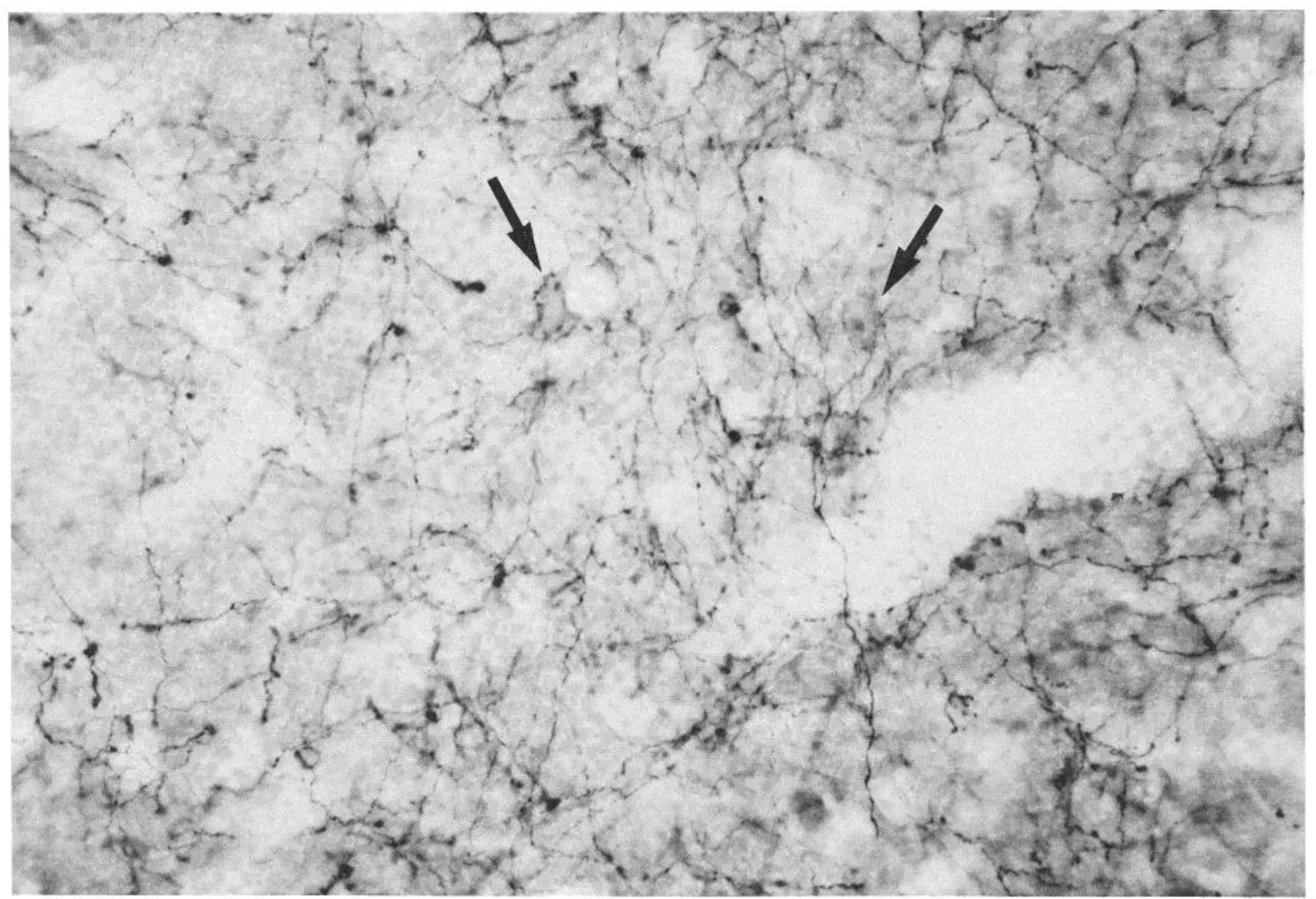

Figure 10. 5-HT fibers at the boundary between layers IVb and IVc in a 60-day-old animal. Note the high density of these fine, varicose fibers. The arrows indicate pericellular arrays of fibers surrounding neurons. Each arrow is $25 \mu \mathrm{m}$ in length. 


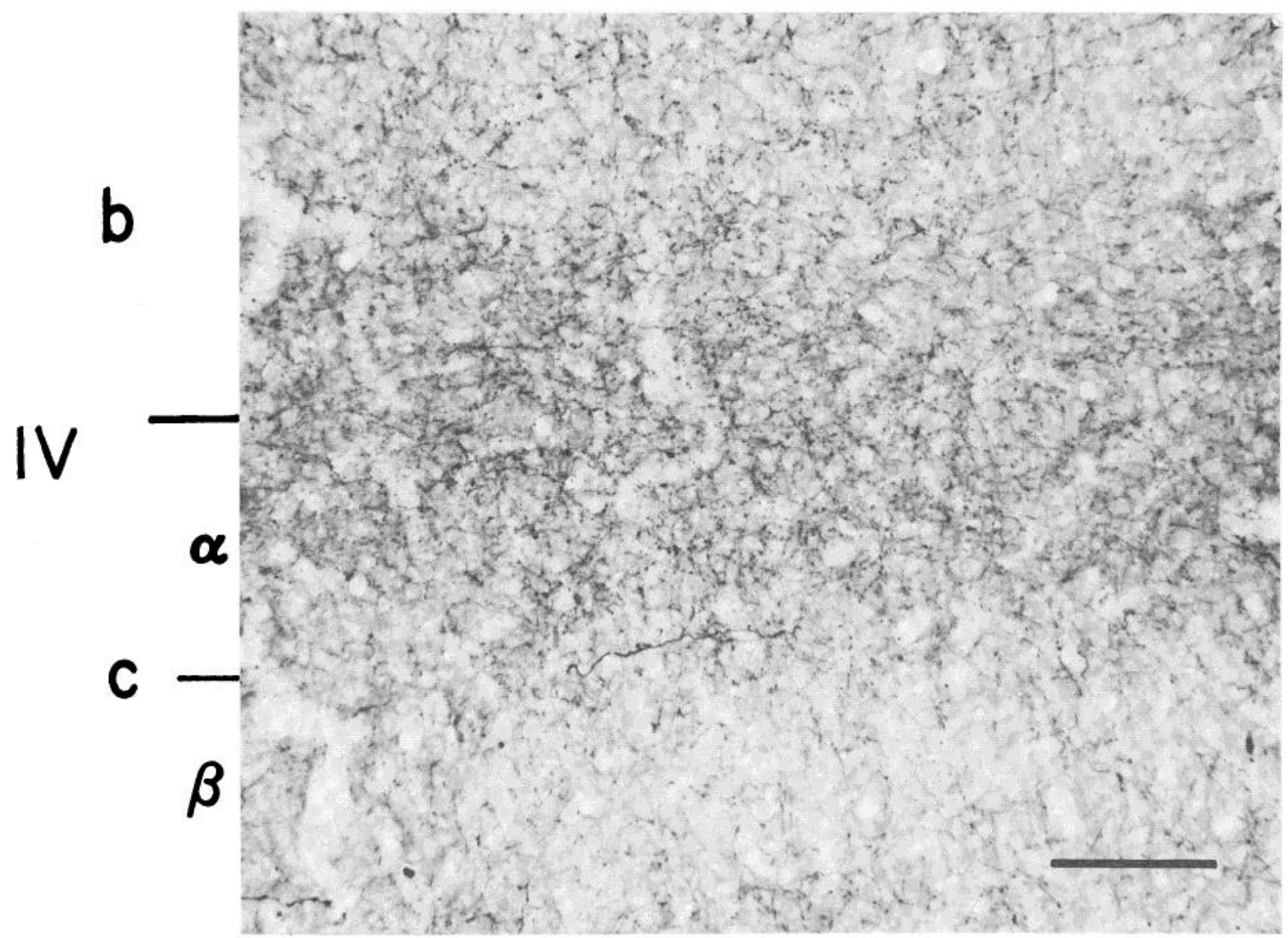

Figure 11. 5-HT fibers in layer IV in an adult animal. Note the extreme density and arborization of these fine caliber fibers. Calibration bar $=$ $100 \mu \mathrm{m}$.

more dense at all ages examined. In the primate, 5 -HT and NA also exhibit striking differences in developmental pattern. Initially, 5-HT fibers densely innervate layer IVb and gradually expand their domain. NA fibers, by contrast, initially penetrate all layers sparsely and gradually arborize in those laminae destined to receive substantial innervation. These interpretations must be tempered by possible differences between the two primary antisera in their ability to reveal developing fibers. The present study probably reveals fibers beginning at the onset of transmitter synthesis in terminal regions, an event which may lag behind the structural development of these axons.

Itakura et al. (1981) studied the monoaminergic innervation of area 17 in 6- to 8-week-old kittens with glyoxylic acid histofluorescence and performed ultrastructural studies on glyoxylic acid-treated tissue postfixed with permanganate. The authors suggest that NA fibers (as opposed to 5-HT or dopamine fibers) were preferentially visualized by these methods. Fluorescent fibers were observed in all layers and appeared to arborize most densely in layers II and III. Boutons containing dense-core vesicles were also observed in all layers. Jonsson and Kasamatsu (1983) have also studied the postnatal development of monoamine levels and receptors in the occipital cortex of the cat. Receptor binding for 5-HT and NA developed at a slightly earlier age than did transmitter levels, and the 5HT system seemed to mature earlier than the NA system.

Timing of developmental stages. Our results are compatible with the biochemical data of Goldman-Rakic and Brown (1982) from rhesus monkeys which indicate that, at birth, there is a much higher level of 5-HT than of norepinephrine in occipital cortex. The concentrations of both transmitters increase rap- idly over the next 60 days, by which time they are approaching adult levels. Throughout life, 5-HT levels are approximately 3 times the norepinephrine levels in occipital cortex (see also Brown and Goldman, 1977). Our data may also reflect their observation that catecholamine synthesis shows an inverse relationship to 5 -HT synthesis in a region-by-region analysis (Goldman-Rakic and Brown, 1982). These biochemical results suggest that our histochemical evidence accurately reflects the immaturity of these systems at birth, their rapid development over the next 60 days, and their relative maturity at this age.

Anatomical studies of other aspects of striate cortex development indicate that the first 60 days of life are a period of rapid maturation for other aspects of cortical anatomy. It is possible, for example, that the development of monoaminergic innervation patterns accompanies the gradual maturation of termination sites on target neurons. Golgi studies of developing neurons in monkey area 17 indicate that the number of dendritic spines on various types of neurons increases from birth to postnatal week 8 (Lund et al., 1977; Boothe et al., 1979). This increase is followed in some types of neurons by a less rapid decrease in spine number and in some neurons by a prolonged plateau and then a decrease (Boothe et al., 1979). Ultrastructural studies in the cat (Cragg, 1975) describe an increase in the number of synapses per neuron in area 17 between postnatal day 8 and 7 weeks of age. There is then a reduction in the number of synapses. This suggests that spine counts reflect changes in the number of synapses. Other studies in monkeys indicate that LGN terminals in layer IV initially show overlap between the two eyes and that there is a gradual retraction to well defined ocular dominance columns which begins just before birth and is completed by 3 to 6 weeks 


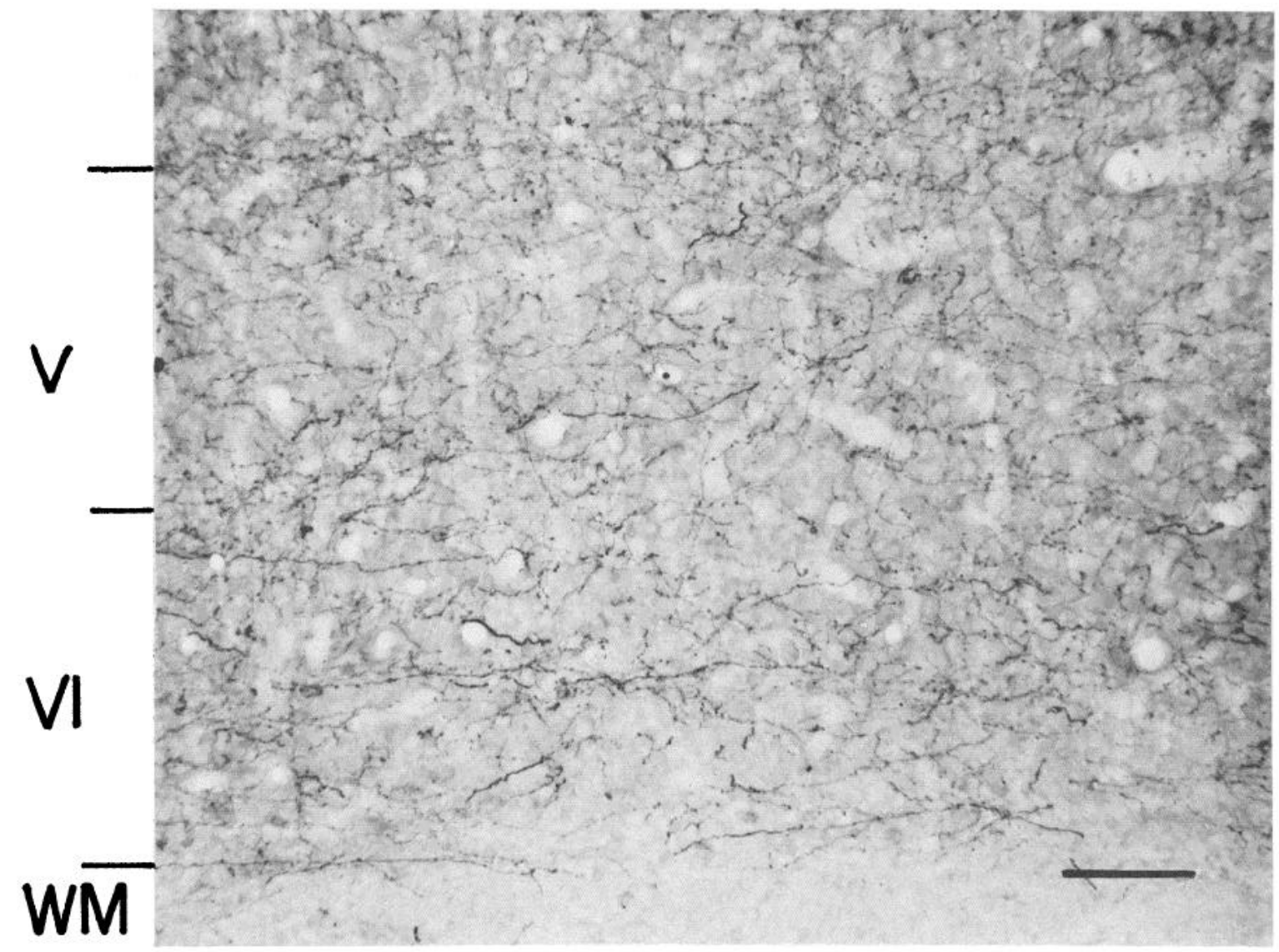

Figure 12. 5-HT fibers in layers V and VI of an adult animal. Note the variability of fiber diameter, ranging from very fine to very coarse, and the predominantly tangential orientation of the coarse fibers. WM, white matter. Calibration bar $=100 \mu \mathrm{m}$.

postnatally (Rakic, 1976; Hubel et al., 1977). Thus, the first several weeks after birth are a period during which spine and synapse numbers peak, thalamic afferents become segregated by eye of origin, ocular dominance and other features exhibit plasticity, and monoaminergic fibers show maturation of adult densities and patterns. Insufficient data are available to characterize the interrelationships among these events. For example, the hypothesis that the elaboration of monoaminergic innervation patterns is dependent upon maturation of cortical target neurons must be tempered by studies in the rat of the effects of antimitotic agents. These studies indicate that monoaminergic fibers produce the same quantity of nerve terminal arborizations even when cortical development is stunted by such agents (Johnston and Coyle, 1979; Johnston et al., 1979; Jonsson and Hallman, 1982).

Functional implications. These monoaminergic systems have been implicated in developmental processes because of their early development in the rat (Olson and Seiger, 1972; Lauder and Bloom, 1974), in the monkey (Levitt and Rakic, 1982), and in humans (Nobin and Bjorklund, 1973; Olson et al., 1973). They have been shown to develop the ability to synthesize their putative transmitters at an early stage of development (Olson and Seiger, 1972; Golden, 1973; Lauder and Bloom, 1974; Choi et al., 1975), and these transmitters have been shown to have complex, long-lasting effects on postysnaptic biochemical processes which might mediate developmental effects (McMahon, 1974). Levitt and Rakic (1982) have demonstrated that in rhesus monkeys the peak genesis of locus ceruleus and many raphe neurons precedes the peak genesis of visual cortex neurons by approximately 45 days (visual cortex data from Rakic, 1974).
There have been reports of specific anatomical changes in neocortical target areas of the NA system in rats after perinatal lesions of the locus ceruleus or its efferents (Maeda et al., 1974; Blue and Parnavelas, 1982; Felten et al., 1982; Parnavelas and Blue, 1982; see also Amaral et al., 1980), although others have reported no such changes (Wendlandt et al., 1977; Ebersole et al., 1981; Lidov and Molliver, 1982b). For the present study, the most relevant claim of dependence of a developmental process on NA innervation is the demonstration that postnatal plasticity in the visual cortex of the cat is dependent upon the integrity of the NA innervation of this cortical region (Kasamatsu and Pettigrew, 1976; Pettigrew and Kasamatsu, 1978; Kasamatsu et al., 1981; Daw et al., 1983), although this finding has been controversial (Bear and Daniels, 1983). Daw et al. (1983) have demonstrated that 6-OHDA administration in visual cortex prevents both ocular dominance plasticity, as previously shown by Kasamatsu and Pettigrew (1976), and plasticity of directional sensitivity. This is of interest since the critical periods for these two types of plasticity differ (Daw and Wyatt, 1976; Berman and Daw, 1977) and the synaptic basis of ocular dominance is different from that of directional sensitivity (Sillito, 1977; Sillito et al., 1981). It should be noted that there has been no demonstration of NA effects on visual cortex plasticity in primates.

Normal development of ocular dominance slabs in area 17 of the monkey depends partially on binocular competition before birth (Rakic, 1981). Our preliminary observations on primary visual cortex obtained from prenatal rhesus monkeys indicate that a dense 5-HT innervation of layer IV is evident at 120 days gestation. The early presence of this dense 5-HT innervation at an age when the NA innervation is still relatively 
Squirrel monkey
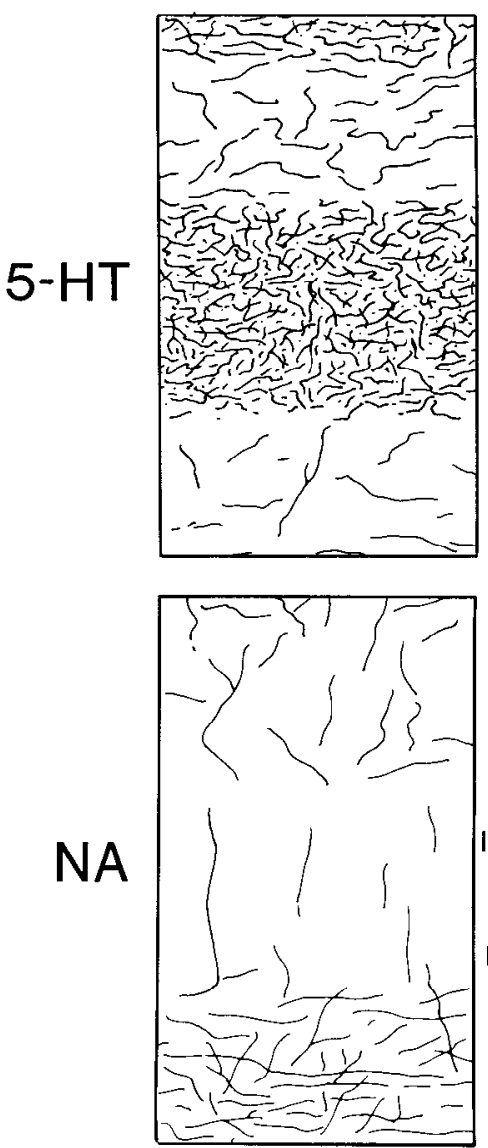

Cynomolgus

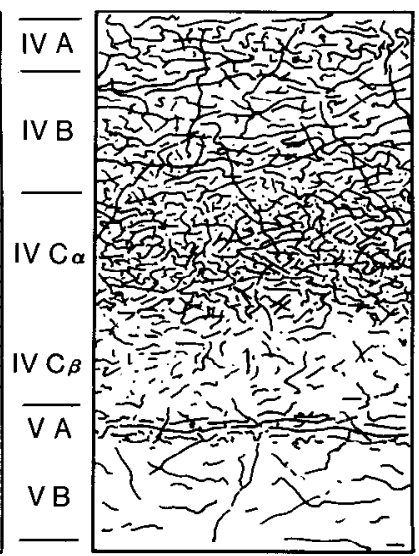

Figure 13. Schematic illustrations of the laminar distributions of 5 HT and NA fibers in primary visual cortex of the squirrel monkey (New World) and the cynomolgus monkey (Old World). Top, 5-HT innervation. Note that each sublamina of layers IVc and V in area 17 of cynomolgus has a distinct terminal pattern and density, whereas in the squirrel monkey the innervation of each of these laminae is homogeneous. Bottom, NA innervation. Note the higher density in layer $\mathrm{IVb}$ of cynomolgus compared to layer $\mathrm{IVb}$ of the squirrel monkey.

sparse, and the fact that the 5-HT innervation is, initially and continually, most dense in layer IV, suggests that $5-\mathrm{H}^{\prime} \mathrm{I}$ may be much more likely to participate in early plasticity, especially of ocular dominance, which seems to depend crucially upon synaptogenic events in this lamina (Rakic, 1976; Hubel et al., 1977; LeVay et al., 1978; Shatz and Stryker, 1978; although see LeVay et al., 1980). LeVay et al. (1980) found that in macaque monkeys ocular dominance plasticity is maximal from birth to 6 weeks of age, coincident with the normal segregation of geniculocortical fibers into ocular dominance zones. Reduced plasticity is evident for 3 more weeks. Thus, plasticity is also inversely proportional to the maturity of monoaminergic innervation patterns, with plasticity no longer being evident once the monoamines have become mature.

There was no evidence in the coronal sections used for this study that the distribution of $5-\mathrm{HT}$ or NA fibers at any age exhibited a correlate of the alternating zones of high and low activity revealed by 2 -deoxyglucose studies in primary visual cortex (Kennedy et al., 1976; Hubel et al., 1978; Hendrickson and Wilson, 1979; Humphrey and Hendrickson, 1983).

Although it is possible that the NA and 5-HT systems mediate some aspect of morphological development, another possibility is that the development of these inputs to area 17 mediates the gradual imposition of brainstem control on cortical activity. Substantial effects of sleep and arousal on cortical visual receptive fields have been described (Livingstone and Hubcl, 1981). These effects are very similar to those produced by iontophoresis of norepinephrine onto visual, auditory, or somatosensory cortex neurons (Foote et al., 1975; Waterhouse and Woodward, 1980; Kasamatsu and Heggelund, 1982; reviewed in Foote et al., 1983).

\section{References}

Amaral, D., G. C. Avendano, and W. M. Cowan (1980) The effects of neonatal 6-hydroxydopamine treatment on morphological plasticity in the dentate gyrus of the rat following entorhinal lesions. J. Comp. Neurol. 194: 171-191.

Bear, M. F., and J. D. Daniels (1983) The plastic response to monocular deprivation persists in kitten visual cortex after chronic depletion of norepinephrine. J. Neurosci. 3: 407-416.

Berman, N., and N. W. Daw (1977) Comparison of the critical periods for monocular and directional deprivation in cats. J. Physiol. (Lond.) 265: 249-259.

Blakemore, C., L. J. Garey, and F. Vital-Durand (1978) The physiological effects of monocular deprivation and their reversal in the monkey's visual cortex. J. Physiol. (Lond.) 283: 223-262.

Blue, M. E., and J. G. Parnavelas (1982) The effect of neonatal 6hydroxydopamine treatment on synaptogenesis in the visual cortex of the rat. J. Comp. Neurol. 205: 199-205.

Boothe, R. G., W. T. Greenough, J. S. Lund, and K. Wrege (1979) A quantitative investigation of spine and dendrite development of neurons in visual cortex (area 17) of Macaca nemestrina monkeys. J. Comp. Neurol. 186: 437-490.

Brown, R. M., and P. S. Goldman (1977) Catecholamines in neocortex of rhesus monkeys: Regional distribution and ontogenetic development. Brain Res. 124: 576-580.

Caviness, V. S., Jr., and M. G. Korde (1981) Monoaminergic afferents to the neocortex: A developmental histofluorescence study in normal and reeler mouse embryos. Brain Res. 209: 1-9.

Choi, B. H., D. S. Antanitus, and L. W. Lapham (1975) Fluorescence histochemical and ultrastructural studies of locus coeruleus of human fetal brain. J. Neuropathol. Exp. Neurol. 34: 507-516.

Coyle, J. T., and M. E. Molliver (1977) Major innervation of newborn rat cortex by monoaminergic neurons. Science 196: 444-447.

Cragg, B. G. (1975) The development of synapses in the visual system of the cat. J. Comp. Neurol. 160: 147-166.

Daw, N. W., and H. J. Wyatt (1976) Kittens reared in a unidirectional environment: Evidence for a critical period. J. Physiol. (Lond.) 257: $155-170$.

Daw, N. W., R. K. Rader, T. W. Robertson, and M. Ariel (1983) Effects of 6-hydroxydopamine on visual deprivation in the kitten striate cortex. J. Neurosci. 3: 907-914.

Ebersole, P., J. G. Parnavelas, and M. E. Blue (1981) Development of the visual cortex of rats treated with 6 -hydroxydopamine in early life. Anat. Embryol. 162: 489-492.

Felten, D. L., H. Hallman, and G. Jonsson (1982) Evidence for a neurotrophic role of noradrenaline neurons in the postnatal development of rat cerebral cortex. J. Neurocytol. 11: 119-135.

Foote, S. L., R. Freedman, and A. P. Oliver (1975) Effects of putative neurotransmitters on neuronal activity in monkey auditory cortex. Brain Res. 86: 229-242.

Foote, S. L., F. E. Bloom, and G. Aston-Jones (1983) Nucleus locus coeruleus: New evidence of anatomical and physiological specificity. Physiol. Rev. 63: 844-914.

Frigon, R. P., D. T. O'Connor, and G. L. Levine (1981) Human dopamine- $\beta$-hydroxylase: Comparison of the enzyme from plasma, adrenal medulla, and pheochromocytoma by radioimmunoassay. Mol. Pharmacol. 19: 444 . 450.

Golden, G. S. (1973) Prental development of the biogenic amine systems of the mouse brain. Dev. Biol. 33: 300-311.

Goldman-Rakic, P. S., and R. M. Brown (1982) Pustnatal development of monoamine content and synthesis in the cerebral cortex of rhesus monkeys. Dev. Brain Res. 4: 339-349.

Hendrickson, A. E., and J. R. Wilson (1979) A difference in $\left[{ }^{14} \mathrm{C}\right]$ deoxyglucose autoradiographic patterns in striate cortex between Macaca and Saimiri monkeys following monocular stimulation. Brain Res. 170: 353-358.

Hubel, D. H., and T. N. Wiesel (1970) The period of susceptibility to the physiological effects of unilateral eye closure in kittens. J. Physiol. (Lond.) 206: 419-436. 
Hubel, D. H., T. N. Wiesel, and S. LeVay (1977) Plasticity of ocular dominance columns in monkey striate cortex. Philos. Trans. R. Soc. Lond. (Biol.) 278: 377-409.

Hubel, D. H., T. N. Wiesel, and M. P. Stryker (1978) Anatomical demonstration of orientation columns in macaque monkey. J. Comp. Neurol. 177: 361-379.

Humphrey, A. L., and A. E. Hendrickson (1983) Background and stimulus-induced patterns of high metabolic activity in the visual cortex (area 17) of the squirrel and macaque monkey. J. Neurosci. 3: $345-358$

Itakura, T., T. Kasamatsu, and J. D. Pettigrew (1981) Norepinephrinecontaining terminals in kitten visual cortex: Laminar distribution and ultrastructure. Neuroscience $6: 159-175$.

Johnston, M. V., and J. T. Coyle (1979) Histological and neurochemical effects of fetal treatment with methylazoxymethanol on rat neocortex in adulthood. Brain Res. 170: 135-155.

Johnston, M. V., R. Grzanna, and J. T. Coyle (1979) Methylazoxymethanol treatment of fetal rats results in abnormally dense noradrenergic innervation of neocortex. Science 203: 369-371.

Jonsson, G., and H. Hallman (1982) Effects of prenatal methylazoxymethanol treatment on the development of central monoamine neurons. Dev. Brain Res. 2: 513-530.

Jonsson, G., and T. Kasamatsu (1983) Maturation of monoamine neurotransmitters and receptors in cat occipital cortex during postnatal critical period. Exp. Brain Res. 50: 449-458.

Kasamatsu, T. (1983) Neuronal plasticity maintained by the central norepinephrine system in the cat visual cortex. Prog. Psychobiol. 10: $1-112$.

Kasamatsu, T., and P. Heggelund (1982) Single cell responses in cat visual cortex to visual stimulation during iontophoresis of noradrenaline. Exp. Brain Res. 45: 317-327.

Kasamatsu, T., and J. D. Pettigrew (1976) Depletion of brain catecholamines: Failure of ocular dominance shift after monocular occlusion in kittens. Science 194: 206-209.

Kasamatsu, T., J. D. Pettigrew, and M. Ary (1981) Cortical recovery from effects of monocular deprivation: Acceleration with norepinephrine and suppression with 6 -hydroxydopamine. J. Neurophysiol. 45: 254-266.

Kennedy, C., M. H. Des Rosiers, O. Sakurada, M. Shinohara, M. Reivich, H. W. Jehle, and L. Sokoloff (1976) Metabolic mapping of the primary visual system of the monkey by means of autoradiographic $\left[{ }^{14} \mathrm{C}\right]$ deoxyglucose technique. Proc. Natl. Acad. Sci. U. S. A. $73: 4230-4234$

Kosofsky, B. E., M. E. Molliver, J. H. Morrison, and S. I. Foote (1984) The serotonin and norepinephrine innervation of primary visual cortex in the cynomolgus monkey (Macaca fascicularis). J. Comp. Neurol., in press.

Kristt, D. A. (1979) Development of neocortical circuitry: Quantitative ultrastructural analysis of putative monoaminergic synapses. Brain Res. 178: 69-88.

Kristt, D. A., and J. D. Silverman (1980) Catecholamine cell groups innervating infant rat somatosensory cortex. Neurosci. Lett. 16:181186

Lauder, J. M., and F. E. Bloom (1974) Ontogeny of monoamine neurons in the locus coeruleus, raphe nuclei and substantia nigra of the rat. I. Cell differentiation. J. Comp. Neurol. 155: 469-482.

LeVay, S., M. P. Stryker, and C. J. Shatz (1978) Ocular dominance columns and their development in layer IV of the cat's visual cortex: A quantitative study. J. Comp. Neurol. 179: 223-244.

LeVay, S., T. N. Wiesel, and D. H. Hubel (1980) The development of oculär dominance columns in normal and visually deprived monkeys. J. Comp. Neurol. 191: 1-52.

Levitt, P., and R. Y. Moore (1979) Development of the noradrenergic innervation of neocortex. Brain Res. 162: 243-259.

Levitt, P., and P. Rakic (1982) The time of genesis, embryonic origin and differentiation of the brain stem monoamine neurons in the rhesus monkey. Dev. Brain Res. 4: 35-57.

Lidov, H. G. W., M. E. Molliver, and N. R. Zecevic (1978) Characterization of the monoaminergic innervation of immature rat neocortex: A histofluorescence analysis. J. Comp. Neurol. 181: 663-680.

Lidov, H. G. W., R. Grzanna, and M. E. Molliver (1980) The serotonin innervation of the cerebral cortex in the rat-An immunohistochemical analysis. Neuroscience 5: 207-227.

Lidov, H. G. W., and M. E. Molliver (1982a) An immunohistochemical study of serotonin neuron development in the rat: Ascending pathways and terminal fields. Brain Res. Bull. 8: 389-430.
Lidov, H. G. W., and M. E. Molliver (1982b) The structure of cerebral cortex in the rat following prenatal administration of 6-hydroxydo pamine. Dev. Brain Res. 3: 81-108.

Livingstone, M. S., and D. H. Hubel (1981) Effects of sleep and arousal on the processing of visual information in the cal. Nature 291: 554561.

Loizou, L. (1972) Postnatal ontogeny of monoamine containing neurons in the central nervous system of the albino rat. Brain Res. 40: $395-418$

Lund, J. A. (1973) Organization of neurons in the visual cortex, area 17, of the monkey (Macaca mulatta). J. Comp. Neurol. 147: 455-496.

Lund, J. S. (1981) Intrinsic organization of the primate visual cortex, area 17, as seen in Golgi preparations. In The Organization of the Cerebral Cortex, eds. F. O. Schmitt, F. G. Worden, G. Adelman, and S. G. Dennis, eds. pp. 105-124, MIT Press, Cambridge, MA.

Lund, J. S., R. G. Boothe, and R. D. Lund (1977) Development of neurons in the visual cortex (area 17) of the monkey (Macaca nemestrina): A Golgi study from fetal day 127 to postnatal maturity. J. Comp. Neurol. 176: 149-188.

Maeda, T., M. Tohyama, and N. Shimizu (1974) Modification of postnatal development of neocortex in rat brain with experimental deprivation of locus coeruleus. Brain Res. 70: 515-520.

McMahon, D. (1974) Chemical messengers in development: A hypothesis. Science 185: 1012-1021.

Molliver, M. E. (1982) Role of monoamines in the development of the neocortex. Neurosci. Res. Program Bull. 20: 492-507.

Molliver, M. E., and D. A. Kristt (1975) The fine structural demonstration of monoaminergic synapses in immature rat neocortex. Neurosci. Lett. 1: 305-310.

Morrison, J. H., S. L. Foote, M. E. Molliver, F, E. Bloom, and H. G. W. Lidov (1982a) Noradrenergic and serontonergic fibers innervate complementary layers in monkey primary visual cortex. Proc. Natl. Acad. Sci. U. S. A. 79: 2401-2405.

Morrison, J. H., S. L. Foote, D. O'Connor, and F. E. Bloom (1982b) Laminar, tangential and regional organization of the noradrenergic innervation of monkey cortex: Dopamine-2-hydroxylase immunohistochemistry. Brain Res. Bull. 9: 309-319.

Nobin, A., and A. Bjorklund (1973) Topography of the monoamine neuron systems in the human brain as revealed in fetuses. Acta Physiol. Scand. Suppl., p. 388.

O'Connor, D.T., R. P. Frigon, and R. A. Stone (1979) Human pheochromocytoma dopamine-1-hydroxylase: Purification and molecular parameters of the tetramer. Mol. Pharmacol. 16:529-538.

Olson, I., and A. Seiger (1972) Farly prenatal ontogeny of central monoamine neurons in the rat: Fluorescence histochemical observations. Z. Anat. Entwicklungsgesch. 137: 301-316.

Olson, L., L. O. Boreus, and A. Seiger (1973) Histochemical demon stration and mapping of 5-hydroxytryptamine- and catecholaminecontaining neuron systems in the human fetal brain. Z. Anat. Entwicklungsgesch. 139: 259-282.

Parnavelas, J. G., and M. E. Blue (1982) The role of the noradrenergic system on the formation of synapses in the visual cortex of the rat. Dev. Brain Res. 3: 140-144.

Pettigrew, J. D., and T. Kasamatsu (1978) Local perfusion of noradrenaline maintains visual cortical plasticity. Nature 271: 761-763.

Rakic, P. (1974) Neurons in rhesus monkey visual cortex: Systematic relation between time of origin and eventual disposition. Science 183: 425-427.

Rakic, P. (1976) Prenatal genesis of connections subserving ocular dominance in the rhesus monkey. Nature 261: 467-471.

Rakic, P. (1983) Development of visual centers in the primate brain depends on binocular competition before birth. Science 214: $928-$ 931.

Schlumpf, M., W. J. Shoemaker, and F. E. Bloom (1980) Innervation of embyronic rat cerebral cortex by catecholamine-containing fibers. J. Comp. Neurol. 192: 361-376.

Seiger, A., and L. Olson (1973) Late prenatal ontogeny of central monoamine neurons in the rat: Fluorescence histochemical observations. Z. Anat. Entwicklungsgesch. 140: 281-318.

Shatz, C. J., and M. P. Stryker (1978) Ocular dominance in layer IV of the cat's visual cortex and the effects of monocular deprivation. J. Physiol. (Lond.) 281: 267-283.

Sherman, S. M., and P. D. Spear (1982) Organization of the visual pathways in normal and visually deprived cats. Physiol. Rev. 62: $738-855$.

Sillito, A. M. (1977) Inhibitory processes underlying the directional 
specificity of simple, complex and hypercomplex cells in the cat's visual cortex. J. Physiol. (Lond.) 271: 699-720.

Sillito, A. M., J. A. Kemp, and C. Blakemore (1981) The role of GABAergic inhibition in the cortical effects of monocular deprivation. Nature 291: 318-320.

Specht, L. A., V. M. Pickel, T. H. Joh, and D. J. Reis (1981) Lightmicroscopic immunocytochemical localization of tryosine hydroxylase in prenatal rat brain. II. Late ontogeny. J. Comp. Neurol. 199: $255-276$.

Steinbusch, H. W. M., A. A. J. Verhofstad, and H. W. J. Joosten (1978) Localization of serotonin in the central nervous system by immunohistochemistry: Description of a specific and sensitive technique and some applications. Neuroscience 3: 811-819.
Takeuchi, Y. and Y. Sano (1983) Immunohistochemical demonstration of serotonin nerve fibers in the neocortex of the monkey (Macaca fuscata). Anat. Embryol. 166: 155-168.

Waterhouse, B. D., and D. J. Woodward (1980) Interaction of norepinephrine with cerebrocortical activity evoked by stimulation of somatosensory afferent pathways in the rat. Exp. Neurol. 67: 11-34.

Wendlandt, S., T. J. Crow, and R. V. Stirling (1977) The involvement of the noradrenergic system arising from the locus coeruleus in the postnatal development of the cortex in rat brain. Brain Res. 125: 19.

Wiesel, 'T. N., and D. H. Hubel (1963) Single-cell responses in striate cortex of kittens deprived of vision in one eye. J. Neurophysiol. 26: 1003-1017. 